\title{
Colorectal cancer with indeterminate pulmonary nodules
}

\author{
Minireview
}

Z. K. JIANG*, Y. K. XIE*, J. Q. HUANG, J. S. CHEN*

Department of Gastrointestinal Surgery, The First Affiliated Hospital of Guangzhou Medical University, Guangzhou 510120, China

${ }^{*}$ Correspondence: hychenjs@126.com

"Contributed equally to this work.

Received June 13, 2019 / Accepted August 26, 2019

\begin{abstract}
Colorectal cancer (CRC) is one of the most common malignancies with a dismal prognosis. Indeterminate pulmonary nodules (IPNs) are lung nodules with uncertain nature, generally defined as a noncalcified nodule smaller than $10 \mathrm{~mm}$ in diameter or solid nodule no greater than $20 \mathrm{~mm}$ at maximum diameter without malignant character. With the widespread use of preoperative staging computed tomography (CT) of the chest and follow-up CT, IPNs are frequently detected in patients with CRC, which makes diagnosis more controversial. Generally, progression to pulmonary metastasis from IPNs is rare. Thus, no further interventions were needed for IPNs in CRC patients. A second reviewing of scans with IPNs by both clinicians and experienced thoracic radiologists may help to obtain a more accurate diagnosis.
\end{abstract}

Key words: indeterminate pulmonary nodule, colorectal cancer, evaluation, management

Colorectal cancer (CRC) is the third most frequent cancer and the second leading cause of cancer associated death [1]. Moreover, the global incidence of CRC is expected to increase substantially in the next decades [2, 3]. The liver is the most common site of distant metastasis from CRC, while lung ranking second $[4,5]$. Pulmonary metastasis has been reported in the range of $10-22 \%$ in all CRC patients [5]. Pulmonary nodules are frequently found in routine preoperative staging computed tomography $(\mathrm{CT})$ and follow-up CT of the chest in CRC patients. However, not all pulmonary nodules are associated with metastatic disease. The issue of determining the nature of lung nodules in CRC patients has received considerable critical attention. The biopsy is the gold standard in determining the nature of lung nodules, but it is traumatic. Moreover, we need to consider several other factors including biopsy complications, costs, technical level, cost-to-performance ratio, patient's condition. Thus, the biopsy may not suitable for all cases. It's difficult for clinicians to define the nature of some pulmonary nodules, which are defined as indeterminate pulmonary nodules (IPNs). The definition of IPNs is varying in different studies. Generally, IPNs were defined as a noncalcified nodule smaller than $10 \mathrm{~mm}$ in diameter or solid nodule no greater than $20 \mathrm{~mm}$ at maximum diameter without malignant character [6].

IPNs are certainly presented in many other cancers including lung cancer, breast cancer [7, 8], liver cancer, bone tumor, head and neck tumors $[9,10]$, and kidney cancer [11]. Given that IPNs were more frequently detected during lung cancer screening or follow-up, the majority of the studies about IPNs are based on lung cancer. There is little published research on colorectal cancer accompanied by IPNs and several aspects of IPNs in colorectal cancer remain unclear which may cause over-treating and over-diagnosing. Further diagnostic workup may delay the time to resection of the index cancer, and is associated with increased radiation exposure, morbidity, costs, uncertainty among doctors and patient anxiety. Therefore, it's urgent to come to a consensus in the management of IPNs in patients with CRC.

In this article, we reviewed the relevant knowledge of IPNs with CRC, aiming to help better understanding of IPNs in CRC. 


\section{The incidence of IPNs in CRC}

In recent years, the incidence of IPNs in CRC patients is reported to range from 4 to $45.5 \%[4,12-23]$. The relevant studies are shown in Table 1. Although the prevalence rates of IPNs in CRC patients vary in different studies, only a small proportion of IPNs progressed into definite metastases [12]. As shown (Table 1), the radios of IPNs that confirmed pulmonary metastasis were reported to range from $5.1 \%$ to $60.7 \%[4,12-23]$.

However, the inclusion and exclusion criteria of the patients and the definition of IPNs in these studies are not consistent. Hence, the comparability between these studies is lacking evidence. Moreover, a larger number of IPNs and a larger number of pulmonary metastases were observed in the patients including distant metastases than in patients without confirmed distant metastases (Table 1). For this reason, we wondered whether there is a difference in the incidence of IPNs among CRC patients with or without distant metastasis. Therefore, we categorized the relevant studies into two main groups according to their inclusion criteria: distant metastasis group (including those underwent resection) and non-distant metastasis group. Interestingly, we found the incidence of IPNs in a distant metastasis group $(10.3 \%, 43 \%$, $16.3 \%, 9 \%, 8.6 \%, 27.2 \%, 7.7 \%$ ) was generally higher than in non-distant metastasis group (4\%, 4.09\%). It seems that the IPNs in CRC patients with extra-thoracic metastases were more likely to be detected. However, the progressing rate in both metastasis group $(20 \%, 35 \%, 50 \%, 10.8 \%, 21 \%, 28.1 \%$, $60.7 \%)$ and non-distant metastasis group $(16.2 \%, 14 \%)$ seemed uncorrelated.

Further researches are required to prove it. Other studies did not elaborate on the inclusion criteria in the aspect of distant metastases. Furthermore, as we can notice in Table 1, most of the recent researches was retrospective. Further prospective studies are needed to elucidate the incidence and nature of IPNs and built the best management for patients with IPNs.

\section{A risk factor of IPNs progressed to pulmonary metastasis}

So far, this paper has focused on IPNs in colorectal carcinoma. Given the previous researches show a predominant incidence rate among high-risk patients with a worse diseasefree survival rate [22], it is important to have a deeper understanding and better evaluation of IPNs. The following section will discuss several factors of IPNs in order to provide a clear understanding for clinicians.

\section{Nodules characteristics}

Location of IPNs. Lung nodule location has been proven to have an influence on the likelihood of malignancy. However, most of the studies were lung-cancer-based and similar studies in the location of IPNs among CRC patients are rare. Previously, several studies had found lung carcinoma more frequently identified in an upper lobe location, especially the right upper lobe [24-25]. Likewise, McWilliams et al. also concluded in a screening trial that the upper lobe location is a risk factor for malignancy [26]. Recently, Fleischner Society management guidelines also approved that pulmonary nodules located in the upper lobe may raise the risk of cancer as high as 5\% [27].

In another aspect, Varol et al. [17] found parenchymal nodules were more likely progressive than subpleural ones which was supported by another study [28] but contrary to the finding of Horeweg et al. [25]. The possible reasons may be the different inclusion criteria of participants. The

Table 1. Incidence and progression rate of IPNs.

\begin{tabular}{|c|c|c|c|c|c|c|c|}
\hline \multirow{2}{*}{ Author } & \multirow{2}{*}{ Year } & \multirow{2}{*}{$\begin{array}{c}\text { Study } \\
\text { type }\end{array}$} & \multirow{2}{*}{$\begin{array}{c}\text { No. of } \\
\text { cases }\end{array}$} & \multirow{2}{*}{$\begin{array}{c}\text { Incidence of } \\
\text { IPNs (\%) }\end{array}$} & \multirow{2}{*}{ Progression rate of IPNs (\%) } & \multicolumn{2}{|c|}{ Characteristics of individuals } \\
\hline & & & & & & Distant metastases $\left(+^{\mathrm{B}} /-^{\mathrm{C}}\right)$ & Index tumor \\
\hline Brent [12] & 2007 & $\mathrm{RP}$ & 439 & $45(10.3 \%)$ & $6 / 30^{\mathrm{A}}(20.0 \%)$ & + & CRC \\
\hline Maithel [13] & 2010 & $\mathrm{R}$ & 160 & $68(43 \%)$ & $24(35 \%)$ & + & CRC \\
\hline Baek [14] & 2012 & $\mathrm{R}$ & 224 & $102(45.5 \%)$ & $6 / 59(10.2 \%)$ & $\mathrm{NM}^{\mathrm{D}}$ & $\mathrm{RC}$ \\
\hline Gomez [15] & 2012 & PR & 184 & $30(16.3 \%)$ & $15(50 \%)$ & + & $\mathrm{CRC}$ \\
\hline Quyn [16] & 2012 & PR & 908 & $37(4 \%)$ & $6(16.2 \%)$ & - & CRC \\
\hline Varol [17] & 2012 & $\mathrm{R}$ & 1344 & $55(4.09 \%)$ & $8(14 \%)$ & - & CRC \\
\hline Griffiths [18] & 2012 & PR & 539 & $28(5.2 \%)$ & $9(32.1 \%)$ & $\mathrm{NM}$ & CRC \\
\hline Nordholm [4] & 2013 & SR & 5873 & $732(9 \%)$ & $10.8 \%$ & + & CRC \\
\hline Hogan [19] & 2014 & $\mathrm{R}$ & 383 & $33(8.6 \%)$ & $7 / 33(21 \%)$ & + & CRC \\
\hline Kim $[20]$ & 2015 & PR & 1195 & $326(27.2 \%)$ & $74 / 263(28.1 \%)$ & + & CRC \\
\hline Nordholm-Carstensen[21] & 2015 & $\mathrm{R}$ & 841 & $9.8 \%$ & $5.1 \%$ & $\mathrm{NM}$ & CRC \\
\hline Robertson [22] & 2017 & $\mathrm{R}$ & 366 & $28(7.7 \%)$ & $17(60.7 \%)$ & + & CRC \\
\hline $\mathrm{Hu}[23]$ & 2018 & $\mathrm{R}$ & NM & 194 & $93(47.9 \%)$ & $\mathrm{NM}$ & CRC \\
\hline
\end{tabular}

$\mathrm{P}$ - prospective, $\mathrm{R}$ - retrospective, $\mathrm{RP}$ - retrospective evaluation of prospectively collected data; A) Follow-up CT scans were only performed in 30 of total 45 individuals and 6 of these 30 patients were progressed into certainly malignancy. The else 15 patients didn't take the follow-up CT due to unknown reasons. B) "+" indicated that the patients were including distant metastasis; C) “-" means that patients were not found to be metastatic; D) NM means - "Not mention". 
NELSON trial was designed as a lung cancer screening. As the NELSON trial described, the inclusion criterion of participants was 'Individuals aged 50 to 75 years, who had smoked 15 or more cigarettes per day for 25 years or 10 or more cigarettes for 30 years and were still smoking or had quit less than 10 years ago. The median age of participants was 58 years-old, of which $16.5 \%$ were female. All participants had a smoking history, of which $55.6 \%$ were current smokers. In Varol's research, participants were diagnosed with CRC with at least one lung nodule identified on a CT scan before treatment. What's more, patients with any distant metastasis, including liver or mediastinum, and patients with already confirmed pulmonary malignancies, including primary lung cancer, were excluded. The main differences between these two researches were listed below: participants in the NELSON trial were all smokers and smoking had been proven as the cause of squamous lung cancer. Participants in Varol's study were all CRC patients detected with pulmonary nodules. In this cohort, those who has extra-thoracic cancer, the lung nodules are detected to be metastases with high risk. Squamous lung cancer is more often found near the pulmonary hila, while metastases tend to be located in the periphery [24]. It leads to the problem of distinguishing between index lung cancer and lung metastasis and it has been proved that the metastatic lung nodules were usually located in the periphery and lower parts of the lungs [29].

Size of a nodule. Size is one of the most important parameters in evaluating lung nodules, especially in predicting malignancy [30]. With the wide use of multi-detector low dose CT scanners, more small pulmonary nodules can be detected. Most pulmonary nodules, in both non-oncological and oncological patients, were detected to be less than 10 $\mathrm{mm}$ in diameter [31].

Previously, Ginsberg et al. had shown that solitary nodules and nodules measuring $10 \mathrm{~mm}$ are more likely to be malignant, and nodules sized $5 \mathrm{~mm}$ are usually benign in patients with known malignancy [32]. On the contrary, Quyn et al. [16] deemed that among the CRC patients, the association between the size of pulmonary and risk of malignancy was insignificant. The diverse result can be attributed to a number of factors, including the heterogenicity of individuals (sex, age, index diseases et al.) and testing technology improvement.

Given that essential treatment, especially chemotherapy, was urgently needed for CRC patients, it should be noticed that the size of pulmonary nodules can be altered when chemotherapy is intervened, which caused the process in differentiating nodules from benign ones unspecific [33]. What's more, it should be noted that the nodule size should be measured by the average of short-axis and longaxis measurements on the same image according to the Fleischner Society guidelines [34]. However, the current measurement of pulmonary nodules was mostly under the 2-D dimension, even in Fleischner Society guidelines' suggestions. A measurement under a 3-D dimension could obtain a better outcome.
In addition, a nodule that appears stable in size in similar projections, also described as a low growth rate in other studies, is considered as benign in subsequent CT scans [3]. One of the important parameters for distinguishing the IPNs from benign to malignant is that the growth rate of benign nodules remains mostly stable while the malignant has the potential to grow larger. Two parameters (the maximum and average diameter of nodules), measured on axial CT image, were commonly used in estimating the growth rate of pulmonary nodules [35]. However, this evaluation has its limitations, such as selecting bias of measuring points caused by radiologists and the low repeatability and reproducibility [36]. Therefore, another parameter, volume doubling time (VDT), was proposed for a more accurate assessment [37]. As the British Thoracic Society guidelines recommended, there were two different volume doubling time (VDT) cut-offs, 400 and 600 days, in differentiating nodules' nature between benign and malignant [38]. A VDT $\leq 400$ days measured by a follow-up CT scan is considered mostly to be malignant while a VDT $>600$ days is remaining conservative without further intervention. Borghesi et al. performed a retrospective study in order to evaluate the priority of the VDT cut-offs of 400 and 600 days. And they found the 600-day VDT cut-off showed better accuracy than the 400-day VDT cut-off in differentiating the nature of IPNs $<300 \mathrm{~mm}^{3}$ [39]. Thus, it could be better to have the following check-up of pulmonary nodules combining size and location while assessing the risk of malignancy.

Calcification of nodules. Calcification is an important indicator for evaluating pulmonary nodules. It could be detected by non-contrast, thin-slice chest-CT. There were several researches proved that IPNs contains fat or calcification centrally inside could be a benign sign in most cases [4, 17]. However, not all the IPNs with calcification were benign. Eccentricity or scattered calcification is highly indicative of malignant lesions, which can be seen in $6 \%$ of lung cancer [40]. Moreover, entire calcification could be seen in osteosarcoma, chondrosarcoma or synovial sarcoma as a result of pulmonary metastases [41]. Therefore, the exclusion of these diseases was needed while assessing calcified IPNs.

Density of nodules. As one of the most important parameters of lung nodules, the significance of nodules density in distinguishing malignant from benign nodules remain controversial. Lung nodules could be classified into three main categories, based on their density, as solid, non-solid, and part-solid (mixed) nodules, in which the "solid nodules" are detected most frequently. Xu et al. assessed the density of lung nodules in size between 50 and $500 \mathrm{~mm}$. And they concluded that baseline nodule density cannot be used to discriminate the nature of IPNs, but it is suggestive for malignancy with an increase in density [42]. However, Kamiya and colleagues found density histogram kurtosis and skewness may be useful for differentiating malignant from benign nodules. But what needs to be noticed is that Kamiya et al. did not perform a histopathological analysis which may 
make the conclusion unreliable [43]. Hence, further studies are needed to identify the relationship between the density and the nature of pulmonary nodules. Furthermore, bilateral nodules, metachronous IPNs, and positive perineural invasion were also illustrated as the risk factors for progression to metastases [20]. However, relevant studies are absent, and more evidence-based researches are needed to prove it. In addition, irregular margins, multiple nodules, older age, history of malignancy, lymph nodes metastases and tobacco exposing leading to higher malignant rate had been proven without any conflicts.

\section{Diagnosis of IPNs}

The diagnosis of IPNs still remains uncertain. Distinguishing between benign and malignant nodules is crucial. If the nodules are malignant, the patient should be treated with lung metastasis resection as soon as possible after proper evaluation. Pulmonary metastasectomy was a potentially curative option in the multimodal management of pulmonary metastases despite the lack of evidence from prospective randomized clinical trials $[44,45]$. If the nodules are confirmed as benign, there is no need to perform surgery.

Previous studies had focused on imaging and tissue biopsy. Tissue biopsy is the gold standard for pathological diagnosis. There are several biopsy methods for pulmonary nodules including thoracotomy, thoracoscopic biopsy, and fine needle aspirate. Thoracotomy is the most effective, but also the most invasive method to obtain a histological diagnosis. Fine needle aspirate may be less invasive with fewer post-complications. However, it's inevitable for fine needle aspirate to take a tissue accurately due to the small size of IPNs. In addition, most of the IPNs are difficult to localize thoracoscopically and the morbidity of a thoracotomy seems unwarranted [16].

The biopsy is the most accurate diagnostic tool for the pathologic confirmation of IPNs. However, it is too difficult or occasionally risky to be performed in most cases, especially for small lesions. Thus, imaging plays an increasingly important role in the diagnosis of IPNs.

$\mathrm{X}$-ray is the most currently used imaging technology in clinical diagnosis. It's quite frequent to discover pulmonary nodules on chest radiography. However, it has limited value in the accuracy of detecting pulmonary nodules either differentiating benign and malignant nodules. In contrast to CT, a false-positive rate of $32.4 \%$ of chest radiography was reported in a recent study, most of which were confounded with images formed by vessels, osseous etiologies, and skin lesions [32].

According to the imaging mechanism, a multidetector chest computed tomography could detect nodules that may be as small as $1-2 \mathrm{~mm}$ in size, whereas X-ray delineates only 5-10 mm nodules [46]. Moreover, the transverse sections of CT provide a more excellent view of shadowed areas such as subpleural or retro-cardiac portions which may be hidden under CXR [47-50]. Thus, chest CT is justified to be more excellent than chest X-ray in both sensitivity and specificity and $\mathrm{CT}$ is the reference standard to characterize pulmonary nodules [51, 52].

Positron emission tomography (PET) can detect the increased glucose metabolism in tumor cells and offer a detailed position at the same time [53]. Thus, PET plays an active role in the detection of distant metastases. However, most of the pulmonary nodules were found $<1 \mathrm{~cm}$ and when comes to nodules $<1 \mathrm{~cm}$, PET imaging is both insensitive and nonspecific [54]. For nodules $<1 \mathrm{~cm}$ in diameter, CT screening could be a better choice. Hence, PET scanning was considered to be unsuitable for detecting IPNs [55, 56]. However, as the technology developing, this view was changing. Recent research assessed the likelihood of malignancy of IPNs by classifying cancer patients into low-, intermediate- and high-risk groups with PET/CT and abnormal PET/CT findings were frequently found in low-risk and intermediate-risk groups [57]. Similarly, in another prospective study, PET/CT scan showed excellent ability in distinguishing between IPNs and malignancy in the follow-up of CRC patients [58]. However, the limitations of PET/CT, the inability of simultaneous acquisition and reduced soft tissue contrast, were still under resolve.

By the way of improving diagnosis with a better outcome, scientists turned to MRI. Recently, a meta-analysis of twelve studies including 524 malignant and 284 benign nodules was performed to identify the value of dynamic contrastenhanced MRI in distinguishing benign from malignant pulmonary nodules with $95 \%$ sensitivity, $87 \%$ specificity. Furthermore, dynamic contrast-enhanced MRI showed great potential in the exclusion of malignant pulmonary nodules [59]. However, the application of MRI in the thoracic cavity is limited due to low signal-to-noise ratio (SNR) in inflatable lung parenchyma and imaging artifacts related to cardiac and respiratory motion [60]. Hence, the fusion of PET and MRI came into notice and this new imaging combination has been just proven to be better than PET/CT or stand-alone PET system with its distinctive combination of anatomical, metabolic and, molecular imaging [61].

On the basis of the Fleischner Society Guideline, we made a diagnostic diagram for IPN (Figure 1). These criteria were mainly according to the characteristics of CT scan and patients' history. Briefly, an IPN is one incidental pulmonary nodule with the following characteristics in CT scan: round opacity, at least moderately well-marginated and no greater than $3 \mathrm{~cm}$ in maximum diameter and excluding non-cancer lung diseases, obvious benign/malignant pulmonary nodules characteristics.

\section{Clinical management}

Although IPNs in colorectal cancer may be benign, it's still significant to take the risk of malignancy into consideration while making clinical management. However, there 
Incidentally found pulmonary nodules with

following characteristics in CT scan:

round opacity, at least moderately well marginated and

no greater than $3 \mathrm{~cm}$ in maximum diameter

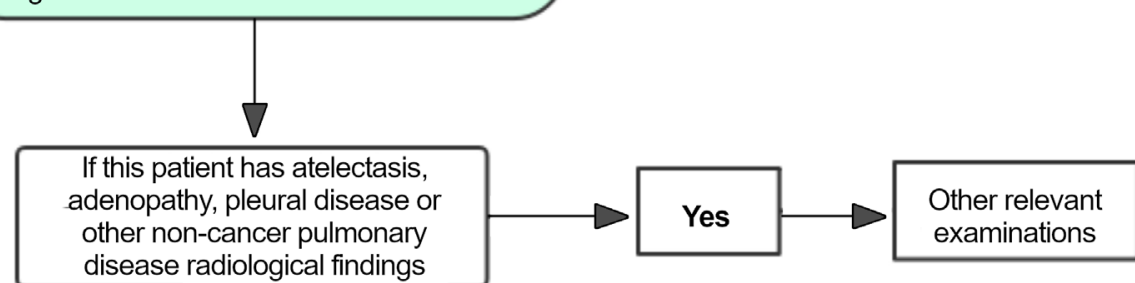

disease radiological findings

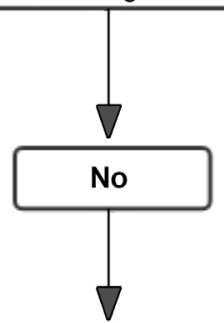

It the incidental pulmonary nodules have following characteristics:

smaller than $4 \mathrm{~mm}$, calcification, irregular margin, multiple nodules or other obvious benign/malingant pulmonary nodules characteristics
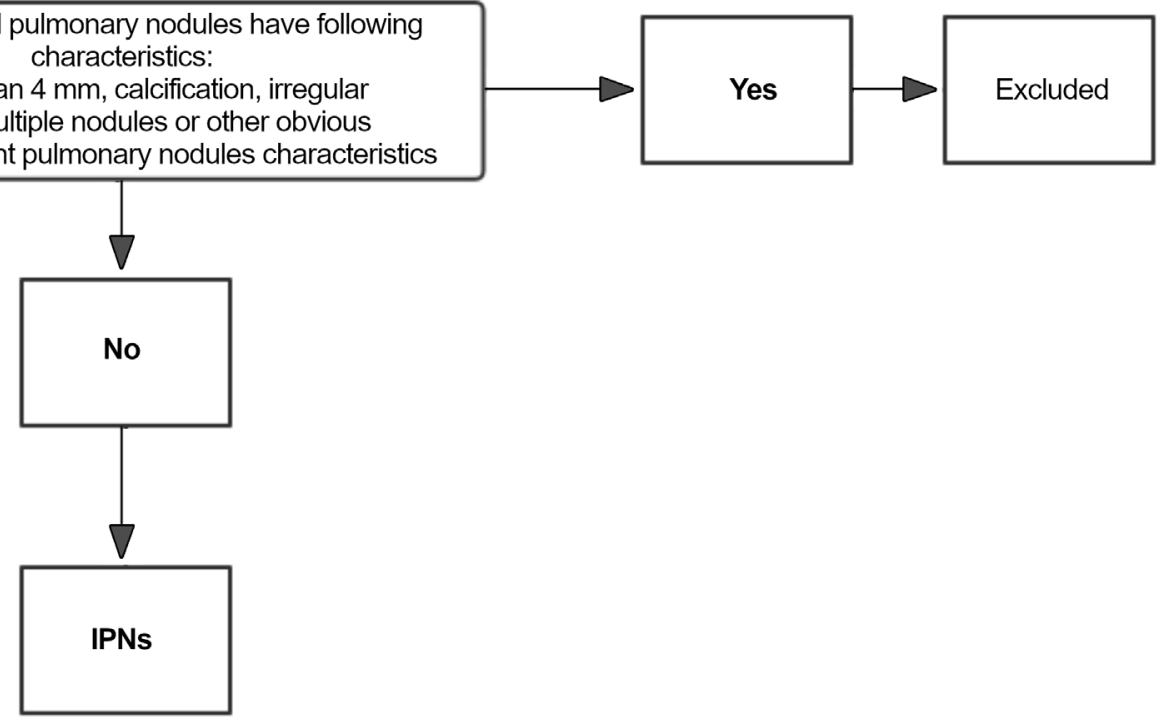

Figure 1. Diagram of diagnosis for IPN

are still no specific guidelines for the management of IPNs though the main idea is no further interventions needed for the management of IPNs with such a low risk for progression $[14,15,18,20]$. There are several core issues among a range of contentions.

\section{Surgery}

As many emerging treatments developing, of which the most influential is a targeted therapy, the surgery is still playing a decisive role in tumors treatment. In cases of pure IPNs, those CRC patients detected with IPNs but without certain metastasis, the management is mainly determined by the risk of malignancy of incidental lung nodules, which can be inferred from data such as nodule size, morphology, and attenuation (i.e., solid or subsolid) [30]. The previous study [15] showed no statistically significant differences between patients with and without IPNs with respect to diseasefree and overall survival. In a cohort of 1344 CRC patients excluding metastasis, Varol et al. [17] observed that only 8 (14\%) of 55 patients in whom indeterminate lung lesions were detected on preoperative CT had progression of lung disease suggesting metastatic disease. Hence, with such a low risk of malignancy, it seems unnecessary to perform further management for IPNs besides routine regimens [4]. Analogously, surgery for IPNs seems to be redundant, although resection of pulmonary colorectal metastases has been proven to associate with improved long-term survival, partic- 
ularly in patients with a solitary metastasis that is suitable for anatomical resection [62]. According to Fleischner Society guidelines [27], the management of incidental pulmonary nodules is based on the likelihood of clinically significant malignancy. The evaluation mainly depends on nodule size, attenuation, morphology, and location. However, regarding those IPNs with metastasis, surgery of resectable metastatic lesions seems to have a positive effect on the improvement of survival rate. Gomez et al. [15] led a research among 184 colorectal cancer survivors with both liver metastases and IPN, and found that a liver resection could promote the survival rate of those who have resectable liver metastases, which was similar to ELSA study [63].

\section{Follow-up}

A preoperative chest CT has been admitted generally in the initial staging procedure due to its excellent imaging quality according to the National Comprehensive Cancer Network (NCCN) [64, 65]. However, the follow-up managements are still controversial because of non-specific morphological characterization and radiological performance of IPNs. Back in 1990, Dinkel et al. [66] proposed that the interval of 3 to 6 months for chest CT follow-up of uncertain nodules has been shown to be appropriate when considering tumor growth dynamics in adenocarcinoma.

Baek et al. [14] took chemotherapy into consideration and recommended that intensive follow-up chest CT or other invasive diagnostic modalities should be considered only in patients with large pulmonary nodules or positive nodal status. In patients receiving adjuvant FOLFOX 4 chemotherapy, thoracic CT scans were performed in high-risk groups, including CRC patients, after 3, 6, and 12 months of initial CT scan, if no interval changes were found in the uncertain lesions. For patients who received adjuvant FOLFOX 4 chemotherapy, the follow-up CT scan was required within 6 months of chemotherapy. If there is no interval change in the high-risk group who receiving FOLFOX 4 chemotherapy, monitoring can begin 6 months after the initial CT, and then $3,6,12$, and 18 months after the second CT.

The Fleischner Society Association recommends a minimum size of $6 \mathrm{~mm}$ for follow-up imaging of incidental nodules, based on a risk assessment greater than or equal to 1 for malignant tumors greater than this threshold. According to the Fleischner Society guidelines, we can infer that followup imaging is not required for CRC patients with solitary solid nodules or multiple solid nodules all less than $6 \mathrm{~mm}$, but can be considered within 12 months, especially if the shape or location of the pulmonary nodules can increase the risk of cancer by up to $5 \%$. Nevertheless, further follow-up of 18 to 24 months is recommended for CRC patients with a single entity of 6 to $8 \mathrm{~mm}$ nodules, since the risk of malignancy of these larger nodules is estimated to be as high as $2 \%$ based on several screening tests $[26,67]$.
For those nodules $8 \mathrm{~mm}$ or larger, follow-up should include CT, PET/CT to determine metabolic activity or tissue sampling. Further examination depends on the patient and clinician, but an image-based malignancy risk assessment should be considered. Even for follow-up, the choice of low-dose CT techniques is necessary to protect patients from the damage of cumulative radiometry $[27,68]$.

\section{IPN and biomarkers}

Although the radiology test improved the detection and management of pulmonary nodules, its value in the diagnosis of IPNs is limited. Molecular biomarkers, developed to assist with the early detection of cancer, have the potential to improve evaluation and prognosis and clinical decision for tumor patients. A molecular biomarker could be invasive or non-invasive/mini-invasive. A non-invasive/mini-invasive biomarker, collected from blood, tumor tissues, sputum or other excretion, with both high sensitivity and specificity, is always catching clinicians' eyes. Up to date, blood remains the most potential source for biomarker discovery due to cellular debris shedding into the bloodstream from the tumor tissues. There's a panel of biomarkers widely used for evaluation of lung cancer and CRC. However, proper biomarkers for the diagnosis of IPNs were rare. One of the early examples of research into biomarkers for IPNs was performed by Patz and colleagues [69]. Patz et al. made an assay within six serum proteins and they found a panel of four serum proteins: carcinoembryonic antigen (CEA), retinol binding protein (RBP), 1-antitrypsin (ATT), and squamous cell carcinoma antigen (SCC) that could distinguish IPN into benign or malignancy (sensitivity $77.8 \%$; specificity $75.4 \%$ ). Based on their previous work, Patz et al. performed extensional research by combining four biomarkers with the lung nodule size and developing multiple models for identification [68]. The overall sensitivity and specificity reached $80-88 \%$ and $82-89 \%$, respectively.

Recently, another study, performed by Xing et al., was designed to identify expressions of 13 sputum miRNAs in two independent parallel cohorts. They found that the sputum miRNA biomarkers may improve the diagnosis of indeterminate solitary pulmonary nodules. The sensitivity and specificity in two cohorts were $82.09 \%, 88.41 \%$ and $80.52 \%, 86.08 \%$, respectively [70]. Besides, other potential biomarkers, such as circulating tumor cells (FR+-CTCs), sputum CA-FISH, plasma biomarker panel, angiogenesis biomarkers (heparin-binding epidermal growth factor (HBEGF), epidermal growth factor (EGF), vascular (V) EGF-A, VEGF-C, and VEGF-D) and autoantibodies (p53, CAGE, NYESO-1, GBU4-5, SOX2, MAGE A4, and Hu-D) have also been reported in previous studies [71-75]. However, the selection of the perfect biomarker from various others makes clinicians confused. Further studies could focus on the combination with different types of biomarkers. 


\section{Histology of IPN}

A relevant study discussing the histology of IPN originating from colorectal cancer vs lung cancer is rare. The main reason to explain this may be that further intervention has been proven to be unnecessary. Most of the studies were simply reporting the nature of IPN as either benign or malignant. However, as we know, almost all colorectal cancer is adenoma-carcinoma and the classifications of colorectal cancer are based on molecular phenotypes. Thus, the histology of IPNs that had been proven to be metastatic colorectal cancer should be adenoma-carcinoma theoretically. If an IPN is confirmed to primary lung cancer, then its histology may conform to lung cancers', mostly to be adenocarcinoma or squamous cell carcinoma [76]. Although a relevant study is lacking, there are some radiological technologies that may use to measure the histopathology of the pulmonary nodules. One example of using radiological technology to measure the histopathology of the pulmonary nodule is computer-aided nodule assessment and risk yield (CANARY), performed by Maldonado and colleagues [77]. They used CANARY to analyze the characterization of pulmonary nodules and categorize the pulmonary nodules into invasive adenocarcinoma (IA), minimally invasive adenocarcinoma (MIA), and adenocarcinoma in situ (AIS), which has the potential in detecting the histology of IPN.

\section{Molecular of IPN}

Although most of the studies are focusing on biomarkers or antigens for diagnosis, prognosis or therapeutics of cancer diseases. Recently, with technology improving, molecular biology has been investigated and practiced into cancer treatment, especially in immunotherapy and targeted therapy. Due to the low-risk of IPN and technological difficulty of biopsy, a direct biopsy of IPN is not preferred. Thus, recent studies on molecular characteristics of IPN in colorectal cancer are focus on the circulating biological products.

As one of the basic technologies of molecular biology, proteomic technology could provide a better understanding of pathomechanism of human disease in protein level. Recently, Codreanu et al. performed multidimensional liquid chromatography-tandem mass spectrometry (LC-MS/ MS) to characterize proteomes of those lung nodules with uncertain nature [78]. They used immunohistochemistry to measure the expression of several proteins: ALOX5, ALOX5AP, ITGAX, SLC2A3, CEACAM6, CRABP2, and LAD1. As a result, they found ALOX5, ALOX5AP, ITGAX, and SLC2A3 were significantly overexpressed in benign nodules compared to lung cancer. This interesting result provided a potential molecular characteristic to distinguish the nature of lung nodule between benign and malignant. However, it didn't discuss the different expression between primary lung cancer and metastatic lung cancer. Further studies could focus on this direction.

\section{Improvement / future directions}

There are still many gaps remaining in our knowledge about CRC and IPNs. Efforts are needed to focus on preventing the under-treatment of CRC with IPNs. However, there are still some methods we could take to improve the diagnosis and management in the clinical situation.

First of all, after collecting information about the disease, performing an MDT (multidisciplinary team) meetings offers an advantage in improving the survival and quality of life among colorectal cancer cohort. A co-reading of films by clinicians and imaging experts, especially expert thoracic radiologist, during the MDT meetings may improve the accuracy of final diagnosis because an expert thoracic radiologist could offer sensitive and appropriate counseling, so that appropriate management and surveillance can be underway. However, although expert thoracic radiologists are the authority in radiology, the characterization of pulmonary nodules on staging CT among CRC differed significantly between the radiologists. To solve this problem, doublereviewing of scans with IPNs is propounded to be a solution [21]. Besides, a better understanding of the biology of the diseases is critical, particularly to confirm the nature of IPNs and to reach a consensus on the definition of IPNs. [13, 79].

For future directions, automated computer analysis of lung nodules is also a topic of ongoing research, with efforts to establish computerized deep learning using huge data sets to better predict potentially malignant lung nodules $[80,81]$. Artificial intelligence is a hot topic in science and it has great prospects in the field of medicine $[82,83]$. Artificial intelligence (AI) holds real potential for improving both the speed and accuracy of medical diagnostics. Professor Dong Nie and his team have designed a new approach: using an AI technique called Deep Convolutional Adversarial Networks to generate and continually improve the simulated images. And this new technology showed great advantages in predicting CT data from corresponding MRI data and converting 3T MRI to 7T MRI [84]. AI may help us better diagnose the disease.

In addition, there are many other new devices or methods show a positive effect in diagnosing IPNs, such as tactile mechanoreceptor [85], digital tomosynthesis [86]. However, more researches are required to prove the value in clinical application.

\section{Conclusion}

In conclusion, IPNs are commonly detected in CRCs, which has been a clinical difficulty for gastroenterologists to make proper decisions for CRC patients. Despite considerable advances in the pathogenesis of colorectal cancer, in the detection of pulmonary nodules, and in diagnosis and treatment of CRC patients with IPNs, a widely accepted guidance in the management of CRC patients with IPNs is lacking. The parallel development of devices and clinical experience is paramount to achieve a better outcome. Clinical and 
basic studies that are in progress will hopefully provide more credible evidence for the management of this cancer.

Acknowledgements: This work was supported by grants from the National Natural Science Foundation of China (81572424), Natural Science Foundation of Guangdong Province (2017A030313482), Guangzhou Municipal Science and Technology Project (201607010164), Scientific Research Project of Guangzhou Municipal Colleges And Universities (1201610322)."

\section{References}

[1] BRAY F, FERLAY J, SOERJOMATARAM I, SIEGEL RL, TORRE LA et al. Global Cancer Statistics 2018: GLOBOCAN Estimates of Incidence and Mortality Worldwide for 36 Cancers in 185 Countries. CA Cancer J Clin 2018; 68: 394-424. https://doi.org/10.3322/caac.21492

[2] ARNOLD M, SIERRA MS, LAVERSANNE M, SOERJOMATARAM I, JEMAL A et al. Global patterns and trends in colorectal cancer incidence and mortality. Gut 2017; 66: 683-691. https://doi.org/10.1136/gutjnl-2015-310912

[3] FURMAN AM, DIT YAFAWI JZ, SOUBANI AO. An update on the evaluation and management of small pulmonary nodules. Future Oncol 2013; 9: 855-865. https://doi.org/10.2217/ fon. 13.17

[4] NORDHOLM-CARSTENSEN A, WILLE-JØRGENSEN PA, JORGENSEN LN, HARLING H. Indeterminate pulmonary nodules at colorectal cancer staging: a systematic review of predictive parameters for malignancy. Ann Surg Oncol 2013; 20: 4022-4030. https://doi.org/10.1245/s10434013-3062-y

[5] SALAH S, WATANABE K, WELTER S PARK JS, PARK JW et al. Colorectal cancer pulmonary oligometastases: pooled analysis and construction of a clinical lung metastasectomy prognostic model. Ann Oncol. 2012; 23: 2649-2655. https:// doi.org/10.1093/annonc/mds100

[6] MASSION PP, WALKER RC. Indeterminate Pulmonary Nodules: Risk for Having or for Developing Lung Cancer? Cancer Prev Res (Phila) 2014; 7: 1173-1178. https://doi. org/10.1158/1940-6207.CAPR-14-0364

[7] CASEY JJ, STEMPEL BG, SCANLON EF, FRY WA. The solitary pulmonary nodule in the patient with breast cancer. Surgery 1984; 96: 801-805.

[8] LEE B, LIM A, LALVANI A, DESCAMPS MJ, LEONARD R et al. The clinical significance of radiologically detected silent pulmonary nodules in early breast cancer. Ann Oncol 2008; 19: 2001-2006. https://doi.org/10.1093/annonc/mdn421

[9] LOH KS, BROWN DH, BAKER JT, GILBERT RW, GULLANE PJ et al. A rational approach to pulmonary screening in newly diagnosed head and neck cancer. Head Neck. 2005 Nov; 27: 990-994. https://doi.org/10.1002/ hed. 20261

[10] MESUROLlE B, MiGNON F, MEINGAN P, DOMENGE $\mathrm{C}$, VASILE $\mathrm{M}$ et al. Head and neck cancer patients with pulmonary nodules: Value and role of CT guided transthoracic needle aspiration biopsies. Head Neck 2003; 25: 889-894.
[11] ADIBI M, KENNEY PA, THOMAS AZ, BORREGALES LD, NOGUERAS-GONZÁLEZ GM et al. Prediction of Pulmonary Metastasis in Renal Cell Carcinoma Patients with Indeterminate Pulmonary Nodules. Eur Urol 2016; 69: 352 360. https://doi.org/10.1016/j.eururo.2015.08.053

[12] BRENT A, TALBOT R, COYNE J, NASH G. Should indeterminate lung lesions reported on staging CT scans influence the management of patients with colorectal cancer? Colorectal Dis 2007; 9: 816-818. https://doi.org/10.1111/ j.1463-1318.2007.01229.x

[13] MAITHEL SK, GINSBERG MS, D’AMICO F, DEMATTEO RP, ALLEN PJ et al. Natural history of patients with subcentimetre pulmonary nodules undergoing hepatic resection for metastatic colorectal cancer. J Am Coll Surg 2010; 210: 31-38. https://doi.org/10.1016/j.jamcollsurg.2009.09.032

[14] BAEK SJ, KIM SH, KWAK JM, CHO JS, SHIN JW et al. Indeterminate pulmonary nodules in rectal cancer: a recommendation for follow-up guidelines. J SURG ONCOL 2012; 4: 481-485. https://doi.org/10.1002/JSO.23106

[15] GOMEZ D, KAMALI D, DUNN WK, BECKINGHAM IJ, BROOKS A et al. Outcomes in patients with indeterminate pulmonary nodules undergoing resection for colorectal liver metastases. HPB (Oxford) 2012; 14: 448-454. https://doi. org/10.1111/j.1477-2574.2012.00474.x

[16] QUYN AJ, MATTHEWS A, DANIEL T, AMIN AI, YALAMARTHI S. The clinical significance of radiologically detected indeterminate pulmonary nodules in colorectal cancer. Colorectal Dis 2012; 14: 828-831. https://doi.org/10.1111/ j.1463-1318.2011.02722.x

[17] VAROL Y, VAROL U, KARACA B, KARABULUT B, SEZGIN $C$ et al. The frequency and significance of radiologically detected indeterminate pulmonary nodules in patients with colorectal cancer. Med Princ Pract 2012; 21: 457-461. https://doi.org/10.1159/000337426

[18] GRIFFITHS SN, SHAIKH I, TAM E, WEGSTAPEL H. Characterisation of indeterminate pulmonary nodules in colorectal cancer. Int J Surg 2012; 10: 575-577. https://doi. org/10.1016/j.ijsu.2012.09.022

[19] HOGAN J, O’ROURKE C, DUFF G, BURTON M, KELLY N et al. Preoperative Staging CT Thorax in Patients with Colorectal Cancer: Its Clinical Importance. Dis Colon Rectum 2014; 57: 1260-1266. https://doi.org/10.1097/ DCR.0000000000000210

[20] Kim CH, Huh JW, Kim HR, Kim YJ. Indeterminate pulmonary nodules in colorectal cancer: follow-up guidelines based on a risk predictive model. Ann Surg 2015; 261: 1145 1152. https://doi.org/10.1097/SLA.0000000000000853

[21] NORDHOLM-CARSTENSEN A, JORGENSEN LN, WILLE-JØRGENSEN PA, HANSEN H, HARLING H. Indeterminate Pulmonary Nodules in Colorectal-Cancer: Do Radiologists Agree? Ann Surg Oncol 2015; 22: 543-549. https://doi.org/10.1245/s10434-014-4063-1

[22] ROBERTSON V, NEAL CP, JONES M, DENNISON AR, GARCEA G. Indeterminate Pulmonary Nodules in Resected Liver Metastases from Colorectal Cancer: A Comparison of Patient Outcomes. World J Surg 2017; 41: 1834-1839. https://doi.org/10.1007/s00268-017-3930-x 
[23] HU T, WANG S, HUANG L, WANG J, SHI D et al. A clinical-radiomics nomogram for the preoperative prediction of lung metastasis in colorectal cancer patients with indeterminate pulmonary nodules. Eur Radiol 2019; 29: 439-449. https://doi.org/10.1007/s00330-018-5539-3

[24] LINDELL RM, HARTMAN TE, SWENSEN S, JETT JR, MIDTHUN DE et al. Five-year lung cancer screening experience: CT appearance, growth rate, location, and histologic features of 61 lung cancers. Radiology 2007; 242: 555-562. https://doi.org/10.1148/radiol.2422052090

[25] HOREWEG N, VAN DER AALST CM, THUNNISSEN E, NACKAERTS K, WEENINK C et al. Characteristics of lung cancers detected by computer tomography screening in the randomized NELSON trial. Am J Respir Crit Care Med 2013; 187: 848-854. https://doi.org/10.1164/rccm.201209-1651OC

[26] MCWILLIAMS A, TAMMEMAGI MC, MAYO JR ROBERTS H, LIU G et al. Probability of cancer in pulmonary nodules detected on first screening CT. N Engl J Med 2013; 369: 910-919. https://doi.org/10.1056/NEJMoa1214726

[27] MACMAHON H, NAIDICH DP, GOO JM, LEE KS, LEUNG ANC et al. Guidelines for management of incidental pulmonary nodules detected on CT images: from the Fleischner Society 2017. Radiology 2017; 284: 228-243. https:// doi.org/10.1148/radiol.2017161659

[28] TAKASHIMA S, SONE S, LI F, MARUYAMA Y, HASEGAWA $\mathrm{M}$ et al. Small solitary pulmonary nodules $(!$ or $=1$ $\mathrm{cm}$ ) detected at population-based CT screening for lung cancer: reliable high-resolution CT features of benign lesions. AJR Am J Roentgenol 2003; 180: 955-964. https://doi. org/10.2214/ajr.180.4.1800955

[29] SNYDER BJ, PUGATCH RD. Imaging characteristics of metastatic disease to the chest. Chest Surg Clin N Am 1998; 8: $29-48$.

[30] ALPERT JB, KO JP. Management of Incidental Lung Nodules Current Strategy and Rationale. Radiol Clin North Am 2018; 56: 339-351. https://doi.org/10.1016/j.rcl.2018.01.002

[31] MISSRIE I, HOCHHEGGER B, ZANON M, CAPOBIANCO J, CÉSAR DE MACEDO NETO A et al. Small low-risk pulmonary nodules on chest digital radiography: can we predict whether the nodule is benign? Clin Radiol 2018; 73: 902-906. https://doi.org/10.1016/j.crad.2018.06.002

[32] GINSBERG MS, GRIFF SK, GO BD, YOO HH, SCHWARTZ LH et al. Pulmonary nodules resected at video-assisted thoracoscopic surgery: aetiology in 426 patients. Radiology 1999; 213: 277-282. https://doi.org/10.1148/ radiology.213.1.r99oc08277

[33] TOYOSHIMA Y, HARA T, MATSUI Y, NAGUMO Y, MAEJIMA A et al. Nodule Size After Chemotherapy and Primary-Tumor Teratoma Components Predict Malignancy of Residual Pulmonary Nodules in Metastatic Nonseminomatous Germ Cell Tumor. Ann Surg Oncol 2018; 25): 3668-3675. https://doi.org/10.1245/s10434-018-6742-9

[34] MACMAHON H, AUSTIN JH, GAMSU G, HEROLD CJ, JETT JR et al. Fleischner Society. Guidelines for management of small pulmonary nodules detected on CT scans: a statement from the Fleischner Society. Radiology 2005; 237: 395-400. https://doi.org/10.1148/radiol.2372041887
[35] DEVARAJ A.; VAN GINNEKEN B.; NAIR A.; BALDWIN D. Use of Volumetry for Lung Nodule Management: Theory and Practice. Radiology 2017; 284: 630-644. https://doi. org/10.1148/radiol.2017151022

[36] REVEL MP, BISSERY A, BIENVENU M, AYCARD L, LEFORT $\mathrm{C}$ et al. Are two-dimensional CT measurements of small noncalcified pulmonary nodules reliable? Radiology 2004, 231: 453-458. https://doi.org/10.1148/radiol.2312030167

[37] BORGHESI A, FARINA D, MICHELINI S, FERRARI M, BENETTI D et al. Pulmonary adenocarcinomas presenting as ground-glass opacities on multidetector CT: Threedimensional computer-assisted analysis of growth pattern and doubling time. Diagn Interv Radiol 2016; 22: 525-533. https://doi.org/10.5152/dir.2016.16110

[38] CALLISTER ME, BALDWIN DR, AKRAM AR, BARNARD S, CANE P et al. British Thoracic Society guidelines for the investigation and management of pulmonary nodules. Thorax 2015; 70: ii1-ii54. https://doi.org/10.1136/thoraxjnl-2015-207168

[39] BORGHESI A, MICHELINI S, SCRIMIERI A, GOLEMI S, MAROLDI R. Solid Indeterminate Pulmonary Nodules of Less Than 300 mm3: Application of Different Volume Doubling Time Cut-offs in Clinical Practice. Diagnostics (Basel) 2019; 9: E62. https://doi.org/10.3390/diagnostics9020062

[40] STEWART JG, MACMAHON H, VYBORNY CJ, POLLAK ER. Dystrophic calcification in carcinoma of the lung: demonstration by CT. AJR Am J Roentgenol 1987; 148: 29-30. https://doi.org/10.2214/ajr.148.1.29

[41] BEIGELMAN-AUBRY C, HILL C, GRENIER PA. Management of an incidentally discovered pulmonary nodule. Eur Radiol 2007; 17: 449-466. HTTPS://DOI.ORG/10.1007/ s00330-006-0399-7

[42] XU DM, VAN KLAVEREN RJ, DE BOCK GH, LEUSVELD AL, DORRIUS MD et al. Role of baseline nodule density and changes in density and nodules features in the discrimination between benign and malignant solid indeterminate pulmonary nodules. Eur J Radiol 2009; 70: 492-498. https://doi. org/10.1016/j.ejrad.2008.02.022

[43] KAMIYA A, MURAYAMA S, KAMIYA H, YAMASHIRO T, OSHIRO Y et al. Kurtosis and skewness assessments of solid lung nodule density histograms: differentiating malignant from benign nodules on CT. Jpn J Radiol 2014; 32: 14-21. https://doi.org/10.1007/s11604-013-0264-y

[44] PFANNSCHMIDT J, DIENEMANN H, HOFFMANN H. Surgical resection of pulmonary metastases from colorectal cancer: a systematic review of published series. Ann Thorac Surg 2007; 84: 324-338. https://doi.org/10.1016/j.athoracsur.2007.02.093

[45] GONZALEZ M, RIS HB, KRUEGER T, GERVAZ P. Colorectal cancer and thoracic surgeons: close encounters of the third kind. Expert Rev Anticancer Ther 2012; 12: 495503. https://doi.org/10.1586/era.12.21

[46] SCHANER EG, CHANG AE, DOPPMAN JL, CONKLE DM, FLYE MW et al. Comparison of computed and conventional whole lung tomography in detecting pulmonary nodules: A prospective radiologic-pathologic study. AJR Am J Roentgenol 1978; 131: 51-54. 
[47] GRIFFITHS EA, BROWELL DA, CUNLIFFE WJ. Evaluation of a preoperative staging protocol in the management of colorectal carcinoma. Colorectal Dis 2005; 7: 35-42. https:// doi.org/10.1111/j.1463-1318.2004.00702.x

[48] ARULAMPALAM TH, COSTA DC, LOIZIDOU M, VISVIKIS D, ELL PJ et al. Positron emission tomography and colorectal cancer. Br J Surg 2001; 88: 176-89. https://doi. org/10.1046/j.1365-2168.2001.01657.x

[49] DAVIS SD. CT evaluation for pulmonary metastases in patients with extrathoracic malignancy. Radiology 1991; 180: 1-12. https://doi.org/10.1148/radiology.180.1.2052672

[50] GIELEN C, SANLI I, STROEKEN L, BOTTERWECK A, HULSEWÉ K et al. Staging chest radiography is not useful in patients with colorectal cancer. Eur J Surg Oncol 2009; 35: 1174-1178. https://doi.org/10.1016/j.ejso.2009.02.012

[51] OST D, FEIN AM, FEINSILVER SH. Clinical practice. The solitary pulmonary nodule. N Engl J Med 2003; 348: 25352542. https://doi.org/10.1056/NEJMcp012290

[52] OKEN MM, HOCKING WG, KVALE PA, ANDRIOLE GL, BUYS SS et al. Screening by chest radiograph and lung cancer mortality: the Prostate, Lung, Colorectal, and Ovarian (PLCO) randomized trial. JAMA 2011; 306: 1865-1873. https://doi.org/10.1001/jama.2011

[53] XU G, ZHAO L, HE ZJ. Performance of whole-body PET/CT for the detection of distant malignancies in various cancers: a systematic review and meta-analysis. J Nucl Med 2012; 53: 1847-1854. https://doi.org/10.2967/jnumed.112.105049

[54] O JH, YOO IER, KIM SH, SOHN HS, CHUNG SK. Clinical significance of small pulmonary nodules with little or no 18F-FDG uptake on PET/CT images of patients with nonthoracic malignancies. J Nucl Med 2007; 48: 15-21.

[55] RUERS T, BLEICHRODT RP. Treatment of liver metastases, an update on the possibilities and results. Eur J Cancer 2002; 38: 1023-1033. https://doi.org/10.1016/s09598049(02)00059-x

[56] HENSCHKE CI, MCCAULEY DI, YANKELEVITZ DF, NAIDICH DP, MCGUINNESS G et al. Early Lung Cancer Action Project: overall design and findings from baseline screening. Lancet 1999; 354: 99-105. https://doi.org/10.1016/ S0140-6736(99)06093-6

[57] EVANGELISTA L, PANUNZIO A, POLVEROSI R, POMERRI F, RUBELLO D. Indeterminate lung nodules in cancer patients: pretest probability of malignancy and the role of 18F-FDG PET/CT. AJR Am J Roentgenol 2014; 202: 507-514. https://doi.org/10.2214/AJR.13.11728

[58] JESS P, SEIERSEN M, OVESEN H, SANDSTRØM H, MALTBÆK $N$ et al. Has PET/CT a role in the characterization of indeterminate lung lesions on staging CT in colorectal cancer? A prospective study. Eur J Surg Oncol 2014; 40: 719-722. https://doi.org/10.1016/j.ejso.2013.11.030

[59] JIANG B, LIU H, ZHOU D. Diagnostic and clinical utility of dynamic contrast-enhanced MR imaging in indeterminate pulmonary nodules: a meta-analysis Clin Imaging 2016; 40: 1219-1225. https://doi.org/10.1016/j.clinimag.2016.08.017

[60] BARJAKTAREVIC I, ARENBERG D, GRIMES BS, RUCHALSKI K, ABERLE DR. Indeterminate Pulmonary Nodules How to Minimize Harm. Semin Respir Crit Care Med 2016; 37: 689-707. https://doi.org/10.1055/s-0036-1592187
[61] MUSAFARGANI S, GHOSH KK, MISHRA S, MAHALAKSHMI P, PADMANABHAN P et al. PETMRI: a frontier in era of complementary hybrid imaging Eur J Hybrid Imaging 2018; 2: 12. https://doi.org/10.1186/s41824-018-0030-6

[62] SALEH W, ALSHAMMARI A, SARRAJ J, ALASHGAR O, AHMED MH et al. Surgical treatment of pulmonary metastasis: report from a tertiary care center. Asian Cardiovasc Thorac Ann 2018; 26: 296-301. https://doi. org/10.1177/0218492318767795

[63] ARVIDE EM, VELASCO JD. Assessment of Overall Survival Benefts in Patients Undergoing Complete Hepatectomy for Synchronous Colorectal Cancer With Liver and Lung Metastases. J Adv Pract Oncol 2016; 7: 788-792. https://doi. org/10.6004/jadpro.2016.7.7.10

[64] National Comprehensive Cancer Network. NCCN clinical practice guidelines in oncology rectal cancer. 2018. http:// www.nccn.org/ professionals/physician_gls/pdf/rectal.pdf

[65] National Comprehensive Cancer Network. NCCN clinical practice guidelines in oncology colon cancer 2018. http:// www.nccn. org/professionals/physician_gls/pdf/colon.pdf

[66] DINKEL E, MUNDINGER A, SCHOPP D, GROSSER G, HAUENSTEIN KH. Diagnostic imaging in metastatic lung disease. Lung 1990; 168: 1129-1136. https://doi.org/10.1007/ bf02718253

[67] HOREWEG N, VAN ROSMALEN J, HEUVELMANS MA, VAN DER AALST CM, VLIEGENTHART R et al. Lung cancer probability in patients with CT-detected pulmonary nodules: a prespecified analysis of data from the NELSON trial of low-dose CT screening. Lancet Oncol 2014; 15: 1332 1341. https://doi.org/10.1016/S1470-2045(14)70389-4

[68] PATZ EF JR, CAMPA MJ, GOTTLIN EB, KUSMARTSEVA I, GUAN XR et al. Panel of Serum Biomarkers for the Diagnosis of Lung Cancer. J Clin Oncol 2007; 25: 5578-5583. https://doi.org/10.1200/JCO.2007.13.5392

[69] PATZ EF JR, CAMPA MJ, GOTTLIN EB, TROTTER PR, HERNDON JE $2^{\mathrm{ND}}$ et al. Biomarkers to Help Guide Management of Patients with Pulmonary Nodules. Am J Respir Crit Care Med 2013; 188: 461-465. https://doi.org/10.1164/ rccm.201210-1760OC

[70] XING L, SU J, GUARNERA MA, ZHANG H, CAI L et al. Sputum microRNA Biomarkers for Identifying Lung Cancer in Indeterminate Solitary Pulmonary Nodules. Clin Cancer Res 2015; 21: 484-489. https://doi.org/10.1158/1078-0432. CCR-14-1873

[71] ZHOU Q, GENG Q, WANG L, HUANG J, LIAO M et al. Value of folate receptor-positive circulating tumour cells in the clinical management of indeterminate lung nodules: A non-invasive biomarker for predicting malignancy and tumour invasiveness. EBioMedicine 2019; 41: 236-243. https:// doi.org/10.1016/j.ebiom.2019.02.028

[72] BARÓN AE, KAKO S, FESER WJ, MALINOWSKI H, MERRICK D et al. Clinical Utility of Chromosomal Aneusomy in Individuals at High Risk of Lung Cancer. J Thorac Oncol 2017; 12: 1512-1523. https://doi.org/10.1016/j. jtho.2017.06.008

[73] DALY S, RINEWALT D, FHIED C, BASU S, MAHON B et al. Development and Validation of a Plasma Biomarker Panel for Discerning Clinical Signifcance of Indeterminate Pulmonary Nodules. J Thorac Oncol 2013; 8: 31-36. https:// doi.org/10.1097/JTO.0b013e31827627f8 
[74] SEDER CW, KUBASIAK JC, PITHADIA R, BASU S, FHIED C et al. Angiogenesis Biomarkers May Be Useful in the Management of Patients With Indeterminate Pulmonary Nodules. Ann Thorac Surg; 100: 429-436. https://doi. org/10.1016/j.athoracsur.2015.04.018

[75] TANG ZM, LING ZG, WANG CM, WU YB, KONG JL. Serum tumor-associated autoantibodies as diagnostic biomarkers for lung cancer: A systematic review and meta-analysis. PLoS One 2017; 12: e0182117. https://doi.org/10.1371/ journal.pone.0182117

[76] MOLINA JR, YANG P, CASSIVI SD, SCHILD SE, ADJEI AA. Non-small cell lung cancer: epidemiology, risk factors, treatment, and survivorship. Mayo Clin Proc. 2008 May; 83(5): 584-594. https://doi.org/10.4065/83.5.584

[77] MALDONADO F, BOLAND JM, RAGHUNATH S, AUBRY MC, BARTHOLMAI BJ et al. Noninvasive characterization of the histopathologic features of pulmonary nodules of the lung adenocarcinoma spectrum using computer-aided nodule assessment and risk yield (CANARY) - a pilot study. J Thorac Oncol 2013; 8: 452-460. https://doi.org/10.1097/ JTO.0b013e3182843721

[78] CODREANU SG, HOEKSEMA MD, SLEBOS RJC, ZIMMERMAN LJ, RAHMAN SMJ et al. Identification of Proteomic Features to Distinguish Benign Pulmonary Nodules from Lung Adenocarcinoma, J Proteome Res. 2017; 16(9): 3266-3276. https://doi.org/10.1021/acs.jproteome.7b00245

[79] GUICHET PL, LIU BY, DESAI B, SURANI Z, CEN SY et al. Preliminary Results of Lung Cancer Screening in a Socioeconomically Disadvantaged Population. AJR Am J Roentgenol 2018; 210: 489-496. https://doi.org/10.2214/AJR.17.18853
[80] JEON KN, GOO JM, LEE CH, LEE Y, CHOO JY et al. Computer-aided nodule detection and volumetry to reduce variability between radiologists in the interpretation of lung nodules at low-dose screening computed tomography. Invest Radiol 2012; 47: 457-461. https://doi.org/10.1097/ RLI.0b013e318250a5aa

[81] REEVES AP, XIE Y, JIRAPATNAKUL A. Automated pulmonary nodule CT image characterization in lung cancer screening. Int J Comput Assist Radiol Surg 2016; 11: 73-88. https://doi.org/10.1007/s11548-015-1245-7

[82] NIBALI A, HE Z, WOLLERSHEIM D. Pulmonary nodule classification with deep residual networks. Int J Comput Assist Radiol Surg 2017; 12: 1799-1808. https://doi. org/10.1007/s11548-017-1605-6

[83] BLUEMKE DA. Radiology in 2018: Are You Working with AI or Being Replaced by AI? Radiology 2018; 287: 365-366. https://doi.org/10.1148/radiol.2018184007

[84] NIE D, TRULLO R, LIAN J, WANG L, PETITJEAN C et al. Medical Image Synthesis with Deep Convolutional Adversarial Networks. IEEE Trans Biomed Eng 2018; 65: 27202730. https://doi.org/10.1109/TBME.2018.2814538.

[85] BARMIN V, SADOVNICHY V, SOKOLOV M, PIKIN O, AMIRALIEV A. An original device for intraoperative detection of small indeterminate nodules. Eur J Cardiothorac Surg 2014; 46: 1027-1231. https://doi.org/10.1093/ejcts/ezu161

[86] QUAIA E, BARATELLA E, POILLUCCI G, GENNARI AG, COVA MA. Diagnostic impact of digital tomosynthesis in oncologic patients with suspected pulmonary lesions on chest radiography. Eur Radiol 2016; 26: 2837-2844. https:// doi.org/10.1007/s00330-015-4104-6 